\title{
BERNARDO SOARES: DESASSOSSEGO E ETERNIDADE
}

Ana Ferraria ${ }^{1}$

Resumo: O Livro do Desassossego pode ser considerado como uma obra atípica de Fernando Pessoa, tanto pela magnitude, comparativamente anómala, de alusões textuais à prosa francesa, como pelo uso potencialmente formalista da linguagem. Pretende-se compreender a relação que Soares cria entre o plano da percepção (exterior) e o plano da emoção (interior), com o objectivo de escrutinar a singularidade do seu livro.

Palavras-chave: Desassossego, História, Memória, Celebridade, Eternidade.

\section{BERNARDO SOARES: DISQUIETUDE AND ETERNITY}

Abstract: The Book of Disquiet may be considered an atypical literary work due to the extent and origin of many of its textual allusions to French prose, which is anomalous in Fernando Pessoa's work, and to the formalist use of language it seems to foreground. The aim of this paper is to understand the relationship Soares builds up between the level of perception (outer) and the level of the emotions (inner), in order to ponder the uniqueness of his book.

Keywords: Disquietude, History, Memory, Celebrity, Eternity.

A celebridade que Pessoa alcançou postumamente contrasta com as características da sua obra. A ideia do autor consagrado parece excluir o acaso e a precariedade da vida e da composição da obra. Se, por um lado, o poeta deixou acumulada, fragmentada, e inédita a maioria dos seus trabalhos, poderia ter-se dado o caso de a sua morte ter sido ainda mais prematura e de a obra potencial não ter nunca deixado de ser apenas isso. Da mesma forma que Sainte-Beuve põe a hipótese da morte de Napoleão antes do advento do Império, ou da morte de Chateaubriand na época do seu combate no exército dos principes $^{2}$ (1904, p. 140), mortes essas que teriam transformado completamente a história do século XIX, imaginese, por outro lado, que Pessoa tivera tempo para completar e editar o Livro do Desassossego: obter-se-ia, podemos com alguma segurança presumi-lo, uma obra distinta de todas as versões que agora possuímos. Visto que o autor não deixou expresso, à hora da morte, os fragmentos que queria, ou não, incluir na versão final do Livro - apenas cerca de 300 trechos se encontravam reunidos num grande envelope com a inscrição «Livro do Desassossego», sendo que outros 200 foram recolhidos com referências ao projeto -, a elaboração editorial transformou-se numa das grandes questões referentes ao mesmo.

\footnotetext{
${ }^{1}$ Doutoranda - Universidade de Lisboa

${ }^{2} \mathrm{O}$ exército dos príncipes (1792) foi formado com o objetivo de lutar contra o novo governo francês.
} 


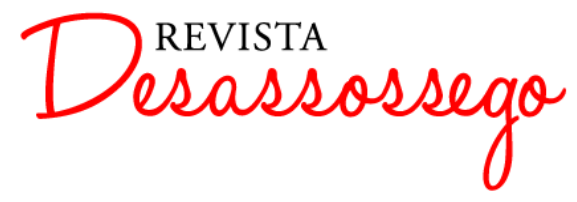

DESASSOSSEGO 15 | JUN/2016 | ISSN 2175-3180

DOI: http://dx.doi.org/10.11606/issn.2175-3180.v8i15p165-177

A descrição da obra pessoana como impessoal, incompleta e fragmentária nomeadamente no que diz respeito à questão da heteronímia - tem como maior expoente os estudos críticos de João Gaspar Simões, Adolfo Casais Monteiro, Jacinto Prado Coelho, Teresa Sobral Cunha, José Augusto Seabra, entre outros. Neste trabalho iremos, contudo, utilizar uma abordagem mais cautelosa, na qual a obra de Fernando Pessoa é vista de forma unitária e apenas fabulosamente dispersa ou fragmentada. O projeto do Livro do Desassossego pode parecer descontínuo; contudo, como Richard Zenith defende, "Pessoa tinha o direito de mudar de ideias" (in PESSOA, 2009, 1, p. 19) e, se não nos é permitido compreender os desígnios reais (ou pelo menos finais) do autor, isso deve-se ao facto de este não ter tido tempo para terminar e rever o seu livro, legando aos filólogos um papel de detetive (PIZARRO, 2014, p. 102) e fazendo do Livro uma construção da posteridade (TABUCCHI, 2000, p. 68).

"A mais deslumbrante obra em prosa de Fernando Pessoa [comenta Zenith, na introdução que faz a uma das suas edições do Livro do Desassossego] uma obra que perdurará como um dos monumentos literários do século XX, nasceu de uma só palavra: desassossego" (in PESSOA, 2009, 1, p. 13). A primeira utilização desta palavra data de 1913, num comentário feito ao lado de um poema, indicando o seu título. Nesse mesmo ano, Pessoa publica na revista A Águia, do Porto, um texto intitulado "Na Floresta do Alheamento", indicado como pertencente ao "Livro do Desassossego, em preparação". Esta foi a primeira referência à obra monumental que o autor iria deixar, em grande parte, inédita até ao momento da sua morte, a 30 de Novembro de 1935. No ano seguinte, em cartas endereçadas a Armando Cortes-Rodrigues, revelará um pouco mais do seu intento: “O que principalmente tenho feito é sociologia e desassossego. V. percebe que a última palavra diz respeito ao 'livro' do mesmo; de facto tenho elaborado várias páginas daquela produção doentia. A obra vai pois complexamente e tortuosamente avançando" (PESSOA, 2007, p. 87). As primeiras impressões sobre o 'livro’ estarão na origem da sua projeção enquanto obra representativa da "depressão profunda e calma" (PESSOA, 2007, p. 91) de que o autor diz padecer no momento da sua escrita. Bernardo Soares ficará conhecido, na sequência da sua caracterização numa célebre carta de Pessoa a Adolfo Casais Monteiro ${ }^{3}$, como um "semi-heterônimo" que se assemelha ao seu criador precisamente nas características que o definem. Para essa ideia, muito contribuirá a biografia de João Gaspar

\footnotetext{
3 A “carta sobre a génese dos heterônimos” data de 13 de Janeiro de 1935.
} 


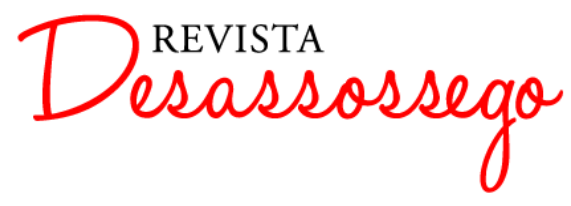

DESASSOSSEGO 15 | JUN/2016 | ISSN 2175-3180

DOI: http://dx.doi.org/10.11606/issn.2175-3180.v8i15p165-177

Simões, na qual se desenha um poeta maldito, profundamente sofrido e desassossegado. A carta a Monteiro pretende que, contudo, salvo o português perfeitamente igual, a vida e o carácter de criatura e criador se distinguem por ser a personalidade do primeiro uma mutilação da do segundo (PESSOA, 2007, p. 429). O Livro do Desassossego tem sido, por isso, geralmente tratado como uma espécie de diário decadentista de um semi-heterônimo pessoano em estado depressivo. Contudo, se existem semelhanças com um diário íntimo, estas são propositadas e ponderadas, como se prova numa carta a Mário de Sá-Carneiro, datada de 14 de Março de 1916, na qual o poeta avisa o amigo para um possível atraso no envio da missiva, de modo a ter tempo "para inserir frases e esgares dela no Livro do Desassossego" (PESSOA, 2007, p. 142). Na verdade, as diferenças entre Pessoa e Soares não se ficam pelo estilo de escrita: segundo Zenith, Pessoa fora mais burguês do que se pensa (PESSOA, 2003, p. 435) e, ao contrário do ajudante de guarda-livros, possuía algum interesse pelo mundo dos negócios (p. 453) e pelo mundo político (p. 473), a família estivera sempre mais ou menos presente na sua vida (p. 449) e a sua assexualidade fora apenas aparente (p. 460). Por todas estas razões, a vida de Pessoa não pôde ser apenas literatura, ao contrário da de Soares, para quem "toda a literatura consiste num esforço para tornar a vida real" (PESSOA, 2009, 1, p. 128).

Segundo a fábula inventada por Pessoa, e descrita num curto prefácio da obra coligida e editada a título póstumo, Bernardo Soares, "um homem que aparentava trinta anos, magro, mais alto que baixo, curvado exageradamente quando sentado, mas menos quando de pé, vestido com um certo desleixo não inteiramente desleixado" (PESSOA, 2009, 1, p. 31), era um dos clientes habituais de um restaurante - taberna decente - que o outro frequentava, em busca de sossego. Ali se conheceram, trocaram frases casuais e se descobriram ambos escritores; talvez, de facto, Soares fosse dos poucos a apreciar, à época, as obras de Pessoa, publicadas de forma dispersa. Numa breve conclusão, Pessoa, editor do Livro do Desassossego, torna inteligível aquele contato, aparentemente fortuito. Soares aproximara-se dele com um único fim: o de proporcionar a publicação do seu livro. De certa forma, este é um livro testamentário e Pessoa, o seu executor. É ele, o primeiro a enumerar as características que perseguirão Soares durante todo o século XX: pessimismo, privação, indiferença e, naturalmente, um nunca terminantemente definido desassossego:

$\mathrm{Na}$ face pálida e sem interesse de feições [escrevera Pessoa no prefácio à obra do outro], um ar de sofrimento não acrescentava interesse, e era 


\section{Desassossego}

DESASSOSSEGO 15 | JUN/2016 | ISSN 2175-3180

DOI: http://dx.doi.org/10.11606/issn.2175-3180.v8i15p165-177

difícil definir que espécie de sofrimento esse ar indicava - parecia indicar vários, privações, angústias, e aquele sofrimento que nasce da indiferença que provém de ter sofrido muito (PESSOA, 2009, 1, p. 31).

Se a temática do sofrimento e do desassossego atravessam recorrentemente a obra de Pessoa, é neste Livro que ganham forma real e compacta. E fazem-no, segundo a nossa tese, não devido a uma necessidade de confessar ao leitor o estado psicológico do autor, mas com o intuito de criar uma obra de arte que possa sobreviver à morte deste.

Como há quem trabalhe de tédio, escrevo, por vezes, de não ter que dizer. $O$ devaneio, em que naturalmente se perde quem não pensa, perco-me eu nele por escrito, pois sei sonhar em prosa. E há muito sentimento sincero, muita emoção legitima, que tiro de não estar sentindo (PESSOA, 2009, 1, p. 145).

A atipicidade desta obra tem origem na combinação de quatro características: a referência comparativamente anômala a escritores de origem francófona; a sua semelhança genérica com um diário íntimo; a presença de descrições virtuosas dos objetos descritos, da cidade e da natureza, que se confundem inextricavelmente com a descrição do sujeito poético; e, por fim, a glorificação do escritor enquanto criador de memória e fixador de história. Bernardo Soares partilha com Fernando Pessoa os tópicos da consciência-de-si e da intromissão da subjetividade do poeta na objetividade da natureza contemplada, transformando ou aniquilando-a: "Aquilo a que assisto e um espetáculo com outro cenário. E aquilo a que assisto sou eu... Meu Deus, meu Deus, a quem assisto? Quantos sou? Quem e eu? O que e este intervalo que há entre mim e mim?” (PESSOA, 2009, 1, p. 198). Estas características são herdadas da tradição literária romântica, à semelhança da qual escreve uma obra cujo protagonista é um anti-herói que tenta justificar a sua condição a futuros leitores, por alegada falta de capacidade em justificá-la a outros interlocutores. O Livro do Desassossego ganha uma forma análoga à da prosa romântica do século XIX, que inclui romances confessionais, romances epistolares ou romances de formação e onde se podem encontrar análises pessoais e do mundo físico, assim como comentários extensos e sistemáticos sobre arte, literatura, política e sociedade. Os autores destas obras são, de resto, diversas vezes, evocados por Soares; neles, salientam-se autores de língua francesa, ao contrário do que acontece na restante obra pessoana. Este facto foi notado por António M. Feijó, que assinala a "extensão do uso de autores de expressão francesa como modelos ou rivais do seu autor - Chateaubriand, Sénancour, Amiel, Vigny, et alii” (2015, p. 143). 


\section{Desassossego}

São fruto da mesma época um Chateaubriand e um Hugo, um Vigny e um Michelet. Mas um Chateaubriand é uma alma grande que diminui... No pai de todos, Jean-Jacques Rousseau, as duas tendências estão juntas. A inteligência nele era de criador, a sensibilidade de escravo (PESSOA, 2011, p. 249).

Segundo Feijó, a tensão que Soares produz, por palavras, entre objetos quotidianos e vulgares e a posição elevada do poeta que deseja ser, assim como o propósito claro de destacar autores de uma língua que lhe é estrangeira ${ }^{4}$, e por isso estranha, revela uma tentativa de estabelecer "as condições iniciais da Literatura” (2015, p.157). Deste prisma, os temas da consciência-de-si e do desassossego serão apenas um género de engodo com que o poeta enseja penetrar a barreira do seu leitor, à semelhança do pedaço de carne que, segundo T. S. Eliot, o poeta-ladrão atira ao cão para lhe assaltar a casa ${ }^{5}$.

A composição de um livro de confissões ou de um diário íntimo ganha relevo durante os séculos XVIII e XIX, nomeadamente no período romântico francês a que JeanJacques Rousseau dá início. Ao analisar um corpus reduzido de prosas confessionais desse período - Les Confessions, de Rousseau, Mémoires d'Outre-Tombe, de Chateaubriand, Oberman, de Senancour, e Journal Intime, de Amiel -, todos referidos e criticados por Soares, foi possível redescobrir a linha que os une e, notavelmente, compreender a influência ou pressão contextual que tiveram no Livro do Desassossego. Numa primeira hipótese, poder-seia admitir que Fernando Pessoa terá usado o Livro do Desassossego para, através do seu heterônimo, produzir uma crítica aos autores que admirava e que o haviam formado, de modo a criar uma distância literária que lhe fosse proveitosa e que justificasse a sua originalidade $^{6}$. Poder-se-ia também incluir este livro no conjunto dos romances de formação, nos quais o protagonista pretende alcançar a maturidade, ao longo do processo da narração. O mesmo podemos supor para as restantes obras analisadas: todas possuem

\footnotetext{
${ }^{4}$ Apesar de a língua francesa não ser realmente estranha a Pessoa, que a lia e escrevia com fluência, não era, no entanto, a sua língua natural, servindo, portanto, para o efeito.

5 Segundo Eliot, o "significado" do poema que o poeta utiliza para "acalmar a cabeça do leitor enquanto o poema faz o seu trabalho" assemelha-se ao pedaço de carne que o ladrão utiliza para iludir o cão de guarda da casa que pretende assaltar (ELIOT, 1975, p. 93). Segundo a teoria formalista da literatura, por outro lado, a poesia pode ser definida como linguagem atenuada e tortuosa e deve ser capaz de fazer perceber objetos quotidianos de uma forma não familiar, vagarosa e estrangeira (SHKLOVSKY, 2010, p. 4). Neste trabalho, considerar-se-á o Livro do Desassossego como uma obra que partilha características com a poesia.

${ }^{6}$ Este mecanismo não é novo, e é famosamente descrito por Harold Bloom, em A Angústia da Influência. Segundo este, os poetas fortes têm a ilusão de se criarem a si próprios, sem sofrerem o jugo dos poetas fortes precedentes. A angústia que nasce desta situação apenas pode ser ultrapassada quando o efebo vence, evade ou mutila o precursor. A consumação da criação do Livro, com a alusão específica aos seus precursores, é a tentativa de Soares de criar algo que, contra todas as evidências, seja apenas seu, e permitir, assim, cunhar na história o seu nome.
} 
um certo carácter documental da vida do protagonista - autor e narrador -, não obstante a possível incoerência ou desordem dos episódios narrados. Todos estes personagens sofrem de desassossego e em todos podemos discernir uma incapacidade de comunicação eficaz com o exterior, que os obriga a fugir da sociedade dos homens - para o campo, para a montanha, para o túmulo ou para um quarto da baixa lisboeta - de modo a procurar uma ataraxia literária, ou calma interior, que possa remir a vida. Ao representarem a decadência da sua época, estes poetas encerram em si um papel anti-heroico ${ }^{7}$ que irá definir e transformar, de forma oculta e indiferente, o padrão de sensibilidade de sociedades futuras (CARLYLE, 1841, p. 98-122).

Não são os sinceros que governam o mundo, mas também não são os insinceros. São os que fabricam em si uma sinceridade real por meios artificiais e automáticos; essa sinceridade constitui a sua forca, e e ela que irradia para a sinceridade menos falsa dos outros. Saber iludir-se bem e a primeira qualidade do estadista... Ver claro e não agir (PESSOA, 2009, 1, p. 240).

Ao se desligar do conceito da sinceridade, crucial para os românticos que o antecedem $^{8}$, Soares incorpora uma estética modernista que utiliza como leitmotiv a cisão entre a consciência do indivíduo e aquilo que lhe é exterior (JACKSON, 2014, p. 30): “o desassossego ... pode ser o outro nome do texto moderno" (MARTINS, 2000, p. 48). Ao contrário de Jean-Jacques, Chateaubriand, Senancour ou Amiel, pouco se sabe sobre a infância ou as influências familiares e mundanas de Soares, a quem Pessoa não doou família, amigos ou interesses materiais:

Parecera a muitos que este diário, feito para mim, é artificial de mais. Mas é de meu natural ser artificial. Com que hei de eu entreter-me, depois, senão com escrever cuidadosamente estes apontamentos espirituais? De resto, não cuidadosamente os escrevo. É, mesmo, sem cuidado limador que os agrupo (PESSOA, 2009, 1, p. 373).

\footnotetext{
${ }^{7}$ Data do início do Romantismo a utilização de um estilo não-elevado, que vem adequar a literatura à vida real e dar lugar ao protagonismo de anti-heróis, que preferem ficar em casa a procurar a fama resultante de uma ação que não lhes pode proporcionar a celebridade real, nem influenciar, de facto, a sociedade.

${ }^{8}$ A sinceridade com que estes autores relatam as suas vidas é, por si só, um tema literário, explorado pelos seus mais célebres comentadores: Sainte-Beuve, Charles Maurras, Jules Lemaittre, Henri Guillemin, Irvin Babbitt, Béatrice Didier, Marc Fumaroli, etc. Para Pessoa, contudo, a sinceridade, e o pacto autobiográfico que a ela associamos, perde relevância: "O poeta superior diz o que efetivamente sente. O poeta médio diz o que decide sentir. O poeta inferior diz o que julga que deve sentir. Nada disto tem que ver com a sinceridade" (PESSOA, 2006, p. 119).
} 


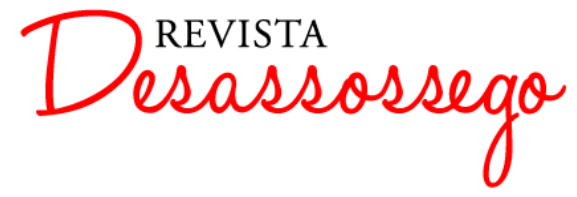

DESASSOSSEGO 15 | JUN/2016 | ISSN 2175-3180

DOI: http://dx.doi.org/10.11606/issn.2175-3180.v8i15p165-177

Perdido entre dois rios ${ }^{9}$, numa sociedade que não entende e em que não se integra, é difícil imaginar que Soares possa dar origem a uma obra com a dimensão das Confissões de Rousseau ou das Memórias de Chateaubriand. E, no entanto, é precisamente esse o objetivo do seu criador, através de uma escolha consciente que não deixa espaço à inclusão de hipotéticas patologias psicológicas: as características que compõem Soares - ou a falta delas - transformam-no no candidato ideal para elaborar uma obra literária sobre a própria literatura. Por outro lado, se os textos de Rousseau e Chateaubriand compreendem uma marca temporal mais ou menos definida (na verdade, os episódios narrados estão, por vezes, e sem prejuízo da obra, deslocados no vetor temporal), nos textos de Senancour, Amiel e, em especial, de Bernardo Soares, a continuidade deixa de ser uma preocupação, transformando-se em fragmento e despersonalização (característica do romantismo tardio, deliberadamente exacerbada pelos modernistas do século XX). Na sequência desta família literária, a indigência projetada em Soares permite-lhe assumir o papel de um anti-herói que prefere ficar em casa a procurar a fama resultante de uma ação que não pode proporcionar a celebridade real, nem influenciar, de facto, a sociedade. O poeta defende, por esse motivo, que a falência advinda da inação é um gênero de vitória: mas uma "vitória majestosa e espiritual” (PESSOA, 2009, 1, p. 261). O seu desassossego e a fragmentação que daí advém enquadram-se perfeitamente no espírito da época: desenvolvendo a posição dos românticos de que descende, Soares priva-se da cidade que não consegue habitar, mas, em vez de procurar atualizar um sonho bucólico, encarcera-se no seu quarto, de onde escreve o seu livro póstumo, as suas memórias de além-túmulo. O seu desassossego torna-se, pois, causa e, principalmente, consequência da escrita.

Apanágio do Romantismo, encontra-se nos trabalhos dos cinco autores estudados uma tendência para a exaltação dos ambientes naturais, através do uso de loco-descrições paisagísticas que potenciam a tensão entre o que é interior ao escritor (o natural, o transcendente, o familiar) e tudo o que lhe é exterior. É a partir desta época, explica Tzvetan Todorov, que a literatura passa a ser encarada como "linguagem não instrumental" que encerra em si própria, por esse motivo, todo o seu valor (1987, p. 15). Segundo Albert Béguin, atribui-se aos primeiros românticos, colocados em frente do espetáculo do universo que pintam, a reflexão sobre o papel da revelação na descoberta de respostas para as suas

\footnotetext{
9 Referência a Chateaubriand, que afirmara sentir-se perdido entre dois séculos, como no desaguar de dois rios (CHATEAUBRIAND, 1998, 3, p. 603).
} 
questões interiores (1937, p. 47). Para Marcel Raymond, é a partir deste período que "todas as imagens se organizam secretamente em símbolos, as palavras deixam de ser signos e passam a participar nas coisas, elas mesmas, nas realidades físicas que evocam", até ao ponto em que, como acontece com Baudelaire, segundo o crítico, o exterior deixa de existir por ele mesmo e transforma-se num depósito de analogias (1985, p. 14, 21). Segundo José Gil, "Cada fragmento transforma-se num acontecimento de escrita, com um devir próprio das imagens e das palavras, com uma espécie de desmetaforização das metáforas, e de realização do movimento metafórico no próprio plano da imaginação verbal” (1994, p. 62). À primeira vista, poderíamos assumir que, para o poeta, as paisagens coexistem com os estados de alma, como sugere Amiel ${ }^{10}$ (AMIEL I, 1911, p. 62), e que os dois objetos se unem num único tema, que rivalizaria com os restantes. No entanto, aquilo que se verifica é que prescrições, confissões, descrições da natureza, críticas a escritores, descrições de objetos comuns e narrações de deambulações têm a mesma dimensão descritiva e são, por isso indiscerníveis entre si. Esta constatação leva a crer que, para o autor, primeiro, todas estas coisas têm um valor intrínseco irrelevante, que pode ser despojado para efeitos descritivos, e, segundo, para efeitos normativos, isto é, quando o objetivo final é escrever um livro, o que interessa ao autor é descrever (e não descrever objetos especificos). Apesar da tentação para identificar propósitos específicos das inúmeras descrições (que pretendem demonstrar movimento ou realçar a lassitude dos personagens, mapear locais, desenhar objetos ao pormenor, prescrever formas de vida ou fazer críticas à sociedade vigente), verifica-se que nada se segue de nenhuma delas:

\begin{abstract}
A razão por que tantas vezes interrompo um pensamento com um trecho de paisagem, que de algum modo se integra no esquema, real ou suposto, das minhas impressões, e que essa paisagem e uma porta por onde fujo ao conhecimento da minha impotência criadora. Tenho a necessidade, em meio das conversas comigo que formam as palavras deste livro, de falar de repente com outra pessoa, e dirijo-me a luz que paira, como agora, sobre os telhados das casas, que parecem molhados de tê-la de lado... (PESSOA, 2009, 1, p. 153).
\end{abstract}

Nestes textos não existem temas, não se aprende nada, e não se consegue distinguir a natureza do resto dos objetos descritos: o seu carácter íntimo, os assuntos que discutem e

\footnotetext{
${ }^{10}$ A teoria de Amiel é comentada múltiplas vezes por Soares: "Disse Amiel que uma paisagem e um estado de alma, mas a frase e uma felicidade frouxa de sonhador débil. Desde que a paisagem e paisagem, deixa de ser um estado de alma. Objetivar e criar, e ninguém diz que um poema feito e um estado de estar pensando em fazê-lo. Ver e talvez sonhar, mas se lhe chamamos ver em vez de lhe chamarmos sonhar, e que distinguimos sonhar de ver" (PESSOA, 2009, 1, p. 93).
} 


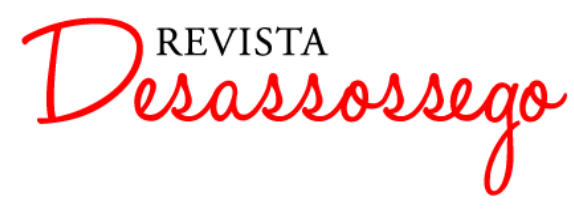

DESASSOSSEGO 15 | JUN/2016 | ISSN 2175-3180

DOI: http://dx.doi.org/10.11606/issn.2175-3180.v8i15p165-177

as descrições de paisagens que incluem servem como pontes descritivas ${ }^{11}$ que ajudam a encadear o discurso. A tensão originada entre as descrições dos céus de Lisboa e as mágoas da vida burocrática de Soares são essenciais para a composição do seu livro: uma tal personagem não poderia ser descrita, nem poderia descrever o patrão Vasques, em outro local que não Lisboa, simplesmente porque, em outros lugares, o livro e o seu narrador seriam diferentes, tudo (o interior e o exterior) se teria de transformar, originando episódios e personagens distintos.

Dizer que o objetivo da vida de Soares é escrever (PÊGO, 2007, p. 126), equivale a dizer que escrever é a vida de Soares; logo, escrever sobre a vida equivale a escrever sobre a escrita, o que cria um de círculo vicioso a que apenas a morte pode dar fim. Apenas a morte interrompe a transformação ininterrupta de pensamentos em palavras, permitindo, no primeiro plano, a conclusão da obra - de modo a que possa ser apreendida por mais do que o seu autor - e, no segundo, a concretização da vida do autor - cujo objetivo fora concluir a sua obra. O quarto andar da rua dos Douradores serve, portanto, o mesmo desígnio do túmulo de Chateaubriand, para lá do qual este autor adivinhava o fim da tensão entre sair do século para o projetar e recordar o século para o narrar.

De resto, de que servem estas especulações de psicologia verbal? Independentemente de mim, cresce erva, chove na erva que cresce, e o sol doira a extensão da erva que cresceu ou vai crescer; erguem-se os montes de muito antigamente, e o vento passa com o mesmo modo com que Homero, ainda que não existisse, o ouviu (PESSOA, 2009, 1, p. 93).

Ao contrário dos outros heterônimos pessoanos, Bernardo Soares pode observar os objetos (naturais, humanos, relacionais), não como cousas que são o que são (PESSOA, 2001, p. 58, XXIV), mas como matéria para literatura. O Livro do Desassossego adquire, desta forma, um propósito formalista, onde a validade e a economia da linguagem utilizada deixam de ser um critério de valor (SHKLOVSKY, 2010, p. 4). O objetivo de Pessoa é criar uma obra de arte superior, que o possa vir a libertar da vida comum e efémera dos homens. "O fim da arte inferior e agradar, o fim da arte media e elevar, o fim da arte superior e

\footnotetext{
11 As emoções, os raciocínios e as aparentes questões existenciais do autor coexistem, em geral, com as vistas da cidade de Lisboa: esta é uma escolha estratégica para criar uma referência espácio-temporal - uma ponte descritiva - onde o poeta possa reunir, através da condensação, todos os signos verbais que pretende harmonizar. Lisboa, com o seu tempo e os seus habitantes específicos, serve um propósito semelhante ao das paisagens bucólicas de Rousseau ou das montanhas geladas e isoladas de Senancour ou, ainda, do encadeamento histórico que agrega toda a narração de Chateaubriand. Cada um destes temas funciona mais como engodo programático, do que como resultado de um enunciado linguístico.
} 


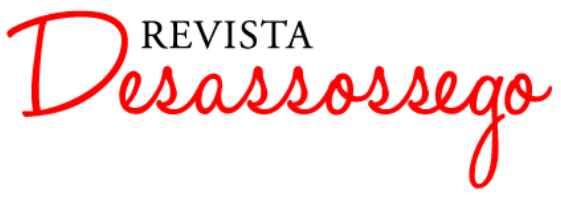

DESASSOSSEGO 15 | JUN/2016 | ISSN 2175-3180

DOI: http://dx.doi.org/10.11606/issn.2175-3180.v8i15p165-177

libertar" (PESSOA, 1969, p. 28). O "pesadelo voluptuoso" que Soares deseja fazer passar aos seus leitores (PESSOA, 2009, 1, p. 200) não é mais do que a materialização da sua liberdade sofrida, liberdade essa que, recorde-se ${ }^{12}$, apenas a larga celebridade lhe poderia conceder. No poema "Tabacaria”, Álvaro de Campos explica que, apesar de não querer ser nada - na vida real, a qual não promete a imortalidade -, tem, em si, todos os sonhos do mundo, todos os sonhos que são motivo de escrita e, portanto, matéria-prima da obra literária. Contudo, a sua ambição e a sua esperança mantêm-se: "E vou escrever esta historia para provar que sou sublime" (PESSOA, 2002, p. 49-51). Com o monumento que pretende edificar, Pessoa pretende inscrever o seu nome na história que, segundo o próprio, é criada pelos escritores, e não pelos heróis comuns. Como se sabe, perdurar não é uma qualidade humana natural; é a inscrição de histórias através de linguagem humana que permite ao homem a ascensão a um plano divino ${ }^{13}$ (ARENDT, 2001, p. 55), e é esse o propósito destes autores. Para lá das coisas que os unem e que os separam, e para lá das descrições e narrações em cada uma das obras, é o seu fim comum que os liga: a necessidade de confissão e de justificação de ações e inações serve, em todos eles, para escrever uma história que redima e legitime as suas vidas, adiando-lhes a morte e proporcionando-lhes a imortalidade literária. Talvez Rousseau, Chateaubriand, Senancour ou Amiel não tivessem esta certeza delineada nas suas mentes, mas, para Pessoa, "a literatura, como toda a arte, é uma confissão de que a vida não basta” (PESSOA, 1969, p. 60). É por a vida não bastar que é preciso desconjuntá-la e re-dispô-la no encalço de um objetivo superior. A vida que Pessoa reconstrói tem de ser, por isso, uma vida desfavorecida e facilmente despedaçável: Soares deve distinguir-se afincadamente do "visconde de Chateaubriand e do senhor professor Amiel", deve fazer contas para ganhar a vida e viver nos Douradores em vez do Boulevard Saint-Germain (PESSOA, 2009, 1, p. 372), não pode ser fidalgo nem burguês (PESSOA, 2009, 1, p. 366) e, portanto, não pode reunir as características do seu criador que o façam assemelhar-se a outros escritores. Se Soares não consegue ver poentes da sua janela, consegue pensar, ainda assim, no "infinito com estrelas

\footnotetext{
12 Referência ao rascunho de uma carta, publicada postumamente, na qual Pessoa enseja revelar a Gaspar Simões a sua esperança de vir a obter fama literária (PESSOA, 2003, p. 196).

${ }^{13}$ Segundo Hannah Arendt, sem a memória, as atividades de ação, palavra e pensamento perder-se-iam com o tempo (ARENDT, 2001, p. 210). Hannah Arendt explica que o ser humano é o único ser "mortal", visto ser o único a percorrer uma linha temporal enquanto indivíduo. $\mathrm{O}$ advento da consciência e da individualidade do homem retira-lhe a imortalidade dos restantes seres vivos, mas permite-lhe, por outro lado, a construção de história. A tarefa da história é, então, salvar as ações humanas da futilidade que advém do esquecimento e é com o propósito de alcançar o mundo imortal que os homens criam arte (ARENDT, 1998, p. 58-61).
} 


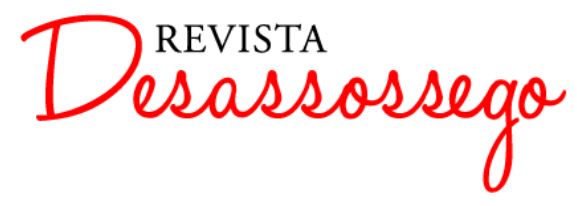

DESASSOSSEGO 15 | JUN/2016 | ISSN 2175-3180

DOI: http://dx.doi.org/10.11606/issn.2175-3180.v8i15p165-177

ao fim” (PESSOA, 2009, 1, p. 367). Através deste seu semi-heterônimo, Pessoa pretende demonstrar que pertence ao grupo mais elevado dos homens superiores - o artista, o gênio -, destronando assim os heróis episódicos que sustentam a economia moral ou a subsistência das sociedades (PESSOA 2006, p. 238). "The wise man stays at home [escrevera Emerson], ...Travelling is a fool's paradise" (2015): se, para Rousseau, Chateaubriand, Senancour e Amiel, viajar pudera ainda ser uma resposta, Soares assume, pela primeira vez, que o futuro pertence àqueles que ficam em casa e olham (e influenciam) o mundo desde a sua janela. Bernardo Soares e o Livro do Desassossego são indistinguíveis entre si porque a vida deste escritor é apenas literatura: "E assim, em imagens sucessivas em que me descrevo - não sem verdade, mas com mentiras -, vou ficando mais nas imagens do que em mim" (PESSOA, 2009, 1, p. 183). Ao criar um livro sobre a literatura, um livro que encerra em si a sua própria edificação, e que exemplifica, ao mesmo tempo que explica, a relação entre a linguagem e a produção literária, Fernando Pessoa conquista a eternidade.

\section{Referências Bibliográficas}

AMIEL, Henri-Frédéric. Fragments d'un Journal Intime Tome I et II. XI édition. Genève: Georg \& C. Libraires Éditeurs, 1911. Comentado por Edmond Scherer.

ARENDT, Hannah. The Human Condition (1958). Trad. Portuguesa Roberto Raposo. Lisboa: Relógio D'Água Editores, 2001.

. "The Modern Concept of History". Trad. Francesa Patrick Lévy in La crise de la culture. Paris: Gallimard, 1998: 58-120. Tradução portuguesa nossa.

BÉGUIN, Albert. L'Ame Romantique et le Rêve. Paris: Librarie José Corti, 1937.

BLOOM, Harold. The Anxiety of Influence (1973). Trad. Miguel Tamen. Lisboa, Edições Cotovia, 1991.

CARLYLE, Thomas, On Heroes, Hero-Worship, and The Heroic in History [1841]. London: The Echo Library, Middlesex, 2007.

CHATEAuBRIAND, François-René. Mémoires d'Outre Tombe. Tome I. Paris: Le Livre de Poche, 1989.

. Mémoires d'Outre Tombe. Tome II. Paris: Le Livre de Poche, 1998, 1.

. Mémoires d'Outre Tombe. Tome III. Paris: Le Livre de Poche, 1998, 2.

. Mémoires d'Outre Tombe. Tome IV. Paris: Le Livre de Poche, 1998, 3.

COELHO, Jacinto Prado. "O Livro do Desassossego, um Falso Diário Íntimo" in Actas do 
$2{ }^{\circ}$ Congresso Internacional de Estudos Pessoanos (1983). Centro de Estudos Pessoanos. Porto. 1985: $579-586$.

DIDIER, Béatrice. Senancour Romancier. Sedes: Paris, 1985.

EMERSON, Ralph Waldo. "Self-Reliance" in Essays: First Series (1841). Web. 8 de Junho 2015. <http://www.emersoncentral.com/selfreliance.htm>.

ELIOT, T.S. "From The Use of Poetry and the Use of Criticism" (1933) in Selected Prose of T.S.Eliot. London: Faber and Faber, 1975: 79-96. Tradução nossa.

FEIJÓ, António M. Uma Admiração Pastoril Pelo Diabo. Lisboa: Imprensa Nacional - Casa da Moeda, 2015.

GIL, José. O Espaço Interior. Lisboa: Editorial Presença, 1994.

JACKSON, K. David. "O Livro do Desassossego e o Journal Intime” in Central de Poesia: O Livro do Desassossego. Lisboa: CLEPUL, 2014: 21-32.

LEJEUNE, Philippe. Le Pacte Autobiographique (1975). Paris: Éditions du Seuil, 1996. $2^{\circ}$ edição.

MARTINS, Fernando Cabral. "O Livro do Desassossego e a escrita heteronímia" in Central de Poesia: O Livro do Desassossego. Lisboa: CLEPUL, 2014: 43-48.

PÊGO, Marisa Isabel Mateus. A Unidade Múltipla de Bernardo Soares. Coimbra: Centro de Literatura Portuguesa, 2007.

PESSOA, Fernando. Cartas. Obra Essencial de Fernando Pessoa 7. Ed. Richard Zenith. Lisboa: Assírio e Alvim, 2007.

Livro do Desassossego. Ed. Richard Zenith. Lisboa: Assirio e Alvim, $1^{\text {a }}$ Ed. 1998. $8^{a}$ Edição de 2009, 1.

. Livro do Desassossego. Obra Essencial de Fernando Pessoa 1. Ed. Richard Zenith. Lisboa: Assírio e Alvim. 1ª Ed. 2006. 4ª Ed. 2011.

. Heróstrato e a Busca da Imortalidade. Obras de Fernando Pessoa. Ed. Richard Zenith. Lisboa: Assírio e Alvim, 2000.

. Páginas Sobre Literatura e Estética. Obras em Prosa de Fernando Pessoa. Org. António Quadros. Mem Martins: Publicações Europa-América, 1969. Poesia de Alberto Caeiro. Obras de Fernando Pessoa. Ed. Fernando Cabral Martins e Richard Zenith. Lisboa: Assírio e Alvim, 2001. $3^{\circ}$ edição 2009, 2. Poesia de Álvaro de Campos, Lisboa: Planeta de Agostini, 2002. Colecção dirigida por Vasco Graça Moura. 
. Prosa Publicada em Vida. Obra Essencial de Fernando Pessoa 3. Ed. Richard Zenith. Lisboa: Assírio e Alvim, 2006.

PIZARRO, Jerónimo. "O Jogo do Desassossego" in Central de Poesia: O Livro do Desassossego. Lisboa: CLEPUL, 2014: 21-32.

RAYMOND, Marcel. De Baudelaire an Surréalisme (1940). Paris: Librarie José Corti, 1985. Tradução nossa.

ROUSSEAU, Jean-Jacques. Les Confessions I. Paris: Garnier-Flammarion, 1968. . Les Confessions II. Paris: Le Livre de Poche, 1972.

SAINTE-BEUVE, Charles Augustin. Chateaubriand et Son Groupe Littéraire sous l'Empire: Vol. II. Paris: Calmann-Lévy, Éditeures, 1904.

SENANCOUR, Étienne Pivert de. Oberman. Edição Fabienne Bercegol. Paris: GarnierFlammarion, 2003.

SHKLOVSKY, Viktor. "Art as Device" in Theory of Prose. Tradução do russo por Benjamin Sher. London: Dalkey Archive Press. Champaign \& London, 1991. 4a impressão 2009.

TABUCCHI, Antonio. Un baule pieno di gente: scritti sur Fernando Pessoa, Milano: Universale Económica Feltrinelli, 2000.

TODOROV, Tzvetan. La Notion de Littérature. Paris: Éditions du Seuil, 1987. 